\title{
Accidental oral administration of povidone iodine in a newborn: case report
}

\author{
Tuğba Alarcon Martinez $M D, P h D^{a}$, Davut Bozkaya, $M D^{a}$, and Murat Yurdakök, $M D^{a}$
}

\begin{abstract}
Iodine solutions are widely used as antiseptic for treating and preventing wound infections. Povidone iodine, one of the most common topical iodine solutions in emergency kits, can lead to several abnormalities as thyroid dysfunction. Povidone iodine poisoning is unusual and previously reported effects are mainly complications of topical usage during surgical procedures. Here we present the case of a newborn that was accidentally given oral povidone iodine, showing no signs or symptoms of toxicity after ingestion.

Key words: newborn, povidone iodine, intoxication.
\end{abstract}

http:/ /dx.doi.org/10.5546/aap.2016.eng.e84

\section{INTRODUCTION}

The antibacterial properties of iodine have been known for more than 150 years, and, at the present, it is widely used as antiseptic for treating and preventing wound infections in daily practice and in preoperative skin preparations. ${ }^{1}$ In some neonatal departments iodine is applied in umbilical cord care; however, some adverse effects due to excess iodine absorption have been reported in preterm and low-birth-weight infants as thyroid dysfunction. Additionally, abnormalities of cardiac conduction, lactic acidosis, acute renal failure, and hypocalcaemia have been also described depending on the severity of intoxication. ${ }^{2}$

Povidone-iodine (PI), a stable chemical complex of polyvinylpyrolidone and elemental iodine, has replaced the widespread use of other iodine solutions as iodine tincture in emergency kits. Nowadays, it is often used topically to disinfect wounds at homes. In spite of its common use, povidone iodine poisoning is unusual

a. Department of Pediatrics Hacettepe University Faculty of Medicine, Ankara, Turkey.

E-mail Address:

Tuğba Alarcon Martinez, MD, PhD: tubaademircii@gmail.com

Funding: None.

Conflict of interest: None.

Received: 6-12-2015

Accepted: 9-18-2015 and previously reported effects are mainly complications of topical usage during surgical procedures. $^{3}$

Mortality due to accidental drug poisoning is increasing all over the world, being the parent's medication administration errors an important factor. ${ }^{4}$ Reporting unusual cases of intoxication by those error types will be valuable for physicians. To our knowledge, no case about the accidental oral administration of povidone iodine has been reported in the literature. Herein, we present the case of a newborn that was accidentally given oral povidone iodine.

\section{CASE}

An 8-day-old female newborn was brought to our emergency room after ingestion of iodine tincture. Her mother reported that she had given two teaspoons of povidone iodine wrongly, instead of the medicine for colic. Immediately after oral intake, her mother understood that it was the wrong drug and washed the mouth of the baby. The baby vomited one time and the parents were not sure about the amount ingested. One hour after the event she was at hospital. On admission to our hospital, physical examination and vital signs were normal. She was given cornstarch and medications for gastroprotection.

On the day of the admission laboratory data showed a TSH level of $6.78 \mathrm{uIU} / \mathrm{mL}$ (N: 0.34$5.60 \mathrm{uIU} / \mathrm{mL}$ ) and a thyroxine (T4) level of 16.46 $\mathrm{pmol} / \mathrm{L}(\mathrm{N}: 8.94-19.05 \mathrm{pmol} / \mathrm{L})$. Urine iodine concentration (125 ug/dl) was high (N: $<100 \mathrm{ug} /$ dl). The baby was closely monitored in newborn department and she was discharged home well after 48 hours. On the $15^{\text {th }}$ day of life, in control examination, the baby was healthy and the thyroid function tests were within normal range.

\section{DISCUSSION}

Iodine is a trace mineral that is needed for the normal metabolism of cells. Its major source is diet. However, in newborn period, several cases showing an over exposure to iodine have been reported after administration of high iodine supplementation to mother in pregnancy or after topical administration of excess iodine solution 
in delivery. The other potential sources of iodine in newborn babies are absorption of excessive amounts of iodine from skin in umbilical care and iodinated contrast media compounds used for cardiac motorization. ${ }^{2}$ Here, we described a new case where iodine was administered accidentally orally.

Beyond the topical antiseptic effect, iodine is sometimes used internally for the irrigation of gastrointestinal (GI) system. However, there are cases reporting the toxic effects of iodine in children after absorption through the gastrointestinal tract. ${ }^{5,6}$ In one of these cases, a 9 weeks old infant was administered povidone iodine through a feeding tube to treat infantile colic, for which this treatment did not show any effectiveness, and he was found dead after the last dose. In addition to high levels of blood iodine, at autopsy, GI tract showed widespread corrosion and necrosis. ${ }^{5}$ This was consistent with the findings of a case series about 18 adults who committed suicide by iodine poisoning and showed corrosive intestinal changes. ${ }^{7}$ In other case, an infant with Hirschsprung's disease developed cardiovascular collapse after having rectal irrigation with povidone-iodine, being exposed to potentially lethal iodine absorption. ${ }^{6}$ Our patient did not develop any GI symptoms, perhaps because the amount ingested was lower compared to these patients or due to the early introduction of starch containing food that reduced the iodine absorption.

On the other hand, another common practice for povidone iodine is disinfection of the face and mucosa lined surfaces of the nose and mouth in head and neck surgeries. There are pediatric case reports revealing that PI aspiration caused chemical pneumonitis with a high rate of morbidity after preoperative disinfection for cleft palate repair. ${ }^{8}$ Our patient did not aspirate the iodine or develop pneumonia. Finally, other very rare complication after povidone iodine topical usage is chemical burn, which was reported on the buttocks of an eight-year-old male after undergoing a laparoscopic appendectomy with antiseptic skin preparation by using povidone iodine solution. ${ }^{9}$

Iodine is an essential element for thyroid hormone synthesis. However, excess iodine levels may cause a transient decrease in thyroid hormone production by inhibiting the organification of iodine. This inhibition serves as a temporary protection against hyperthyroidism, which is known as the acute Wolff-Chaikoff effect. ${ }^{10}$ In adults, an escape from this effect usually occurs in a few days after exposure. On the other hand, immature thyroid glands of newborns are unable to escape from the acute Wolff-Chaikoff effect easily and can not start producing thyroid hormone. Thus, newborns are more susceptible to iodineinduced hypothyroidism. When this transient hypothyroidism is treated by L-thyroxine, a development of newborn without neurological sequelae is usually achieved. ${ }^{3}$ In our case, thyroid hormones were in normal range so we did not give our patient thyroxine treatment.

Besides thyroid dysfunctions, there are other signs of iodine intoxication as abnormalities in cardiac conduction, lactic acidosis, acute renal failure, hypocalcaemia. ${ }^{2}$ Although our patient had mildly elevated urine iodine level, she did not show any symptoms of iodine intoxication. Our findings are consistent with a case reported in a medical bulletin of a Turkish hospital where accidentally a newborn ingested povidone iodine instead of vitamin d supplementation. ${ }^{11}$ Here, the authors also found no signs or symptoms of toxicity after povidone iodine ingestion. In literature, there are only few reports about ingestion of iodine solutions and one of this is an adult case where intentional ingestion of iodine tincture led to severe hemolysis and acute renal failure. ${ }^{12}$ As we said, our patient did not have as severe symptoms as this, probably because the ingestion was accidental and amount was less.

As accidental intoxication with iodine is a rare form of poisoning, there are limited publications as to optimal management of these patients. We reviewed toxicology databases and literature to obtain the best treatment for this case. ${ }^{13,14}$ Since early administration of starch containing food was suggested to convert iodine to the much less toxic iodide, we gave our patient cornstarch. Starchy food was suggested for our patient by the poison control center.

Poisoning is a significant public health issue for children and the majority of poisonings involving young children are classified as unintentional. In our case, parent's drug administration error was the reason of intoxication. However, it is shown that 95 percent of the cases, the poisoning occurred because the child ingested the drug, as opposed to a labeling or dosage error by parents or health care worker. ${ }^{4}$ An important caution for reducing the risk of poisoning in children via the ingestion of potentially hazardous items is to use effective child-resistant (CR) packaging 
in medications and household chemicals. Still, a substantial proportion of child poisonings involves products dispensed in CR packages that were defeated or left insecure at the time of ingestion. For this reason, the most fundamental approach is developing a general education program on primary prevention. Health officials, the media, and community outreach must all help to increase awareness about the dangers of poisoning and preventive measures. In this information based strategies, health care providers especially pediatricians are in a position to play an important role in communicating with families. Educating parents about intensified child supervision, safe storage of drugs, proper drug dosage and administration will prevent poisonings. ${ }^{4,15}$ In our case, the iodine intoxication was due to parent's drug administration error. The medication for infantile colic and povidine iodine was stored in the same place, so the mother gave the wrong drug. This case shows that the accurate labelling of the drugs and safe medication storage can be important in prevention of drug administration errors.

In conclusion, we report a new way (orally) of excess iodine in newborn in which no related toxicity occured.

\section{REFERENCES}

1. Durani P, Leaper D. Povidone-iodine: use in hand disinfection, skin preparation and antiseptic irrigation. Int Wound J 2008;5(3):376-87.

2. Pennington JA. A review of iodine toxicity reports. J Am Diet Assoc 1990;90(11):1571-81.
3. Oliver Llinares F, Azpeitia Palomo A, Alfonso Sánchez L, González Landa G, et al. Neonatal hypothyroidism secondary to the use of povidone-iodine. Cir Pediatr 1989;2(4):168-71.

4. Hughes RG, Edgerton EA. Reducing pediatric medication errors: children are especially at risk for medication errors. Am J Nurs 2005;105(5):79-80.

5. KurtTL,Morgan ML,Hnilica V, Bost R, et al. Fatal iatrogenic iodine toxicity in a nine-week old infant. J Toxicol Clin Toxicol 1996;34(2):231-4.

6. Means LJ, Rescorla FJ, Grosfeld JL. Iodine toxicity: an unusual cause of cardiovascular collapse during anesthesia in an infant with Hirschsprung's disease. J Pediatr Surg 1990;25(12):1278-9.

7. Finkelstein R, Jacobi M. Fatal iodine poisoning: a clinicopathologic and experimental study. Ann Intern Med 1937;10(9):1283-96.

8. Chepla KJ, Gosain AK. Interstitial pneumonitis after betadine aspiration. J Craniofac Surg 2012;23(6):1787-9.

9. Rees A, Sherrod Q, Young L. Chemical burn from povidoneiodine: case and review. J Drugs Dermatol 2011;10(4):414-7.

10. Bürgi H. Iodine excess. Best Pract Res Clin Endocrinol Metab 2010;24(1):107-15.

11. Can E, BülbülA, UsluS, BolatF, et al. Yenidogan döneminde iyod intoksikasyonu: Olgu sunumu. The Medical Bulletin of Sisli Etfal Hospital 2009;43(4):187-8.

12. Mao YC, Tsai WJ, Wu ML, Ger J, et al. Acute hemolysis following iodine tincture ingestion. Hum Exp Toxicol 2011;30(10):1716-9.

13. Toxicology data network [Internet]. Bethesda (MD): U.S. National Library of Medicine; 2006. Iodine, Elemental. [Accessed on: september 18, 2015] Available from: http:/ / toxnet.nlm.nih.gov/cgi-bin/sis/search/a?dbs+hsdb:@ term+@DOCNO+34.

14. Wax PM. Antiseptics, disinfectants, and sterilants. In: Nelson LS, Lewin NA, Howland MA, Hoffman RS, et al, eds. Goldfrank's Toxicologic Emergencies. 9th ed. New York: McGraw-Hill; 2011.Págs.1345-57.

15. Vaida AJ. The Institute for Safe Medication Practices and Poison Control Centers: collaborating to prevent medication errors and unintentional poisonings. J Med Toxicol 2015;11(2):262-4. 